\title{
An Assessment of Volatility Models: A Case Study for Borsa Istanbul (BIST)
}

\author{
Cantürk KAYAHAN \\ Bolvadin School of Applied Sciences, Department of Banking and Finance \\ Afyon Kocatepe University, Turkey. \\ Tuğrul KANDEMİR \\ Department of Management \\ Afyon Kocatepe University. Turkey \\ Ender BAYKUT \\ Department of Management in English, \\ Afyon Kocatepe University, Turkey. \\ Cahit MEMIS \\ Expert, RiskMetrics Institution, İstanbul, Turkey.
}

\begin{abstract}
Strong volatility forecasts in making financial decisions play an important role for financial institutions and other users. In practice, volatility models like the MA, EWMA and GARCH are used as volatility outlook. Particularly GARCH and EWMA type volatility forecasting models perform better in capturing fluctuations and developments in financial markets than the models that assume the variance is constant. However, results of these models turn out to be close to each other and comparing the results of calculations performed on the same underlying asset does not bear much meaning. Therefore in this study, comparisons with HL volatility models have also been made to better capture the differences between the volatility models. Volatility calculations of this study have been made by using the GARCH (1.1) base model and over USD/TL exchange rate and ISE 30 index between the dates 06/30/2008 06/30/2009. Comparisons between predictions of the models have been performed by MSPE, CW and DMW tests and significant differences between GARCH (1.1) model and HL volatility model have been determined.
\end{abstract}

Keywords: Forecasting, Volatility, Risk

\section{INTRODUCTION}

Since the start of floating exchange rate system in the early 1970s there have been continuous intense discussions until present day regarding the impact of foreign exchange rates on international trade (Cheong, 2004, p. 1) Today no financial analyst can disregard the importance of volatility forecast methods in future oriented decision making processes (Suganuma, 2000, p. 1). That said, we can give some answers to the question of which method should be used in forecasting the volatility. When the literature studies are assessed it is seen that there are findings showing the negative and positive effects of exchange rate fluctuations.

In today's financial markets volatility forecasts are frequently used in asset management, portfolio management and pricing derivative products. They play key role for financial markets 
(McMillan and Speight, 2004, p. 1). Financial institutions in particular, need to measure their portfolio risks to determine their capital requirements.

While these calculations are made the prime issue to take into consideration is the volatility coefficients. J.P. Morgan was the first financial institution which opened up its own risk management methodology, RiskMetrics, to the use of other financial institutions. In later years RiskMetrics became a very influential benchmark in risk management applications (Suganuma, 2000, p. 1). Nonetheless, volatility calculations employed by RiskMetrics have been criticized from a number of perspectives. For instance, RiskMetrics asset returns calculations have been assumed to have normal distribution. In EWMA volatility and covariance calculation between assets, the same decay factor has been used.

In the following years, many academics and experts have argued that the EWMA (Exponential Weighted Moving Average) model and other models could also be used in volatility calculations and they could provide even better results. In addition to this, alternative volatility and risk measurement models derived from time series data have been presented. However, the debate about which method provides better volatility forecast results remains open.

The first part of this study summarizes assessments about the concept, development and basic characteristics of volatility and literature review. In the second part volatility models used in the study and their notations are presented. In the third part, calculations of the volatilities of the ISE 30 index and USD/TRL exchange rate using the MA (Moving Average), EWMA (Exponential Weighted Moving Average) and GARCH (Generalized Autoregressive Conditional Heteroscedasticity) models, as well as HL (Historical High Low Volatility) models were performed. Using the GARCH (1.1) model as the base model, the results of the various volatility models have been compared by utilizing MSPE (Mean Square Prediction Error), DMW (Diebold, Mariano and West) and CW (Clark and West) performance tests.

\section{The Concept Of Volatility And Its Development}

The first studies on volatility contracts date back to $1700 \mathrm{~s}$ BC when the first option contracts were used. They were used in particular by farmers who did not want to get affected by poor weather. This was one of the first examples of risk management used in those times. The first derivative market transactions on forward products were developed at Royal Stock Exchange in 1637. On the other hand, development of derivative markets has been accelerated by using mathematical tools developed for pricing and hedging purposes. Despite Bachelior's dissertation written at the beginning of 1900s and which attracted much applause, the use of first option contracts on commodity markets occurred after the publication of the Black Scholes model in 1973. Until the 1990s financial markets concentrated on the expected return of an asset and on observing the data. These studies assumed that price changes of financial assets had a normal distribution (Schmidt, 1995, p. 1110). However, today volatility forecasts constitute the most important inputs for some asset pricing models. The need for exact forecasts of volatility is critically important to determine derivative asset pricing, capital budgeting, portfolio selection and financial risk management (Pereira, 2007, p. 4). Therefore, for all parties concerned, volatility estimates are an unwelcome necessity.

\section{Concept of Volatility}

There are differing views on how to measure volatility. For example, Giannopoulos and Eales (1996, p. 46) define the volatility as the "uncertainty around forecast value of a financial asset". According to Butler (1999, p. 190) volatility is the statistical measurement of the price change in the financial instrument. According to Brooks and Persand (2003, p.2) volatility "is measured by standard deviation of portfolio returns and it is uniquely important in financial 
markets for it is often taken to represent the portfolio's risk". Hampton $(2005$, p. 3) on the other hand describes volatility as "the measure showing the extent of price movements in stocks, future contracts or other financial instruments". Finally, from a statistical perspective Poon (2005. p XV) considers the volatility as the standard deviation. Additionally, volatility can be considered as a risk indicator however risk and volatility should not be regarded the same, because, while risk assumes the probability of encountering unwanted results, volatility allows for possible positive outcomes as well. These two important differences between volatility and risk are often disregarded (Poon, 2005, p. 1).

In today's world, being able to make some predictions about the future is extremely important for the financial analysts. However, there is not a full agreement among the experts as to which model should be used, either. The root cause for this lack of consensus is the fact that different volatility models provide different results.

The data used in financial analyses, the sources these data are derived from, and the time interval used all greatly determine the efficacy of the study. For this reason, basic elements contained in financial data have been grouped under four major headings in RiskMetrics (1996, p. 64). These are as follows:

- Financial time series return distributions frequently have "fat tails",

- The peak of the return distribution is higher and narrower than that predicted by the normal distribution.

- Volatility changes over time,

- Returns have small autocorrelations while squared returns often have significant autocorrelations.

In simple volatility models financial data have been evaluated on three fundamental assumptions. These assumptions are: (i) returns are independent of each other and they have the same returns, (ii) average of returns is zero and (iii) the variance of returns is constant (Unal, 2009, p. 20). However, in the later periods the fact that variance will not be constant or it will change over time has been shown primarily by RiskMetrics and later by the studies of Robert M Engle (1982). Following this, such volatility models as ARCH and GARCH that assume variance would change over time have been developed. Finance theories are frequently predicated on assumptions related to structure of price information (such as securities, exchange rates and interest rates). The globalization trends in financial system have made it mandatory for financial institutions and many firms operating in real sectors to calculate their risks. After all, future is uncertain and managing this uncertainty is directly related to accurate measurement of variation in the financial asset in question. However, before moving into analyses based on volatility, understanding the basic characteristics of volatility will significantly affect the assessments made.

Mougeot, (2005, p. 14) explains the basic characteristics of volatility as follows: The values that

- jump after market crashes and shocks,

- demonstrate the trend of returning to average in the long run (reversal)

- test the low and low rates,

- generally show negative correlation with asset returns that are under liability or obligation

Table 1 shows the variation observed in American dollar. Particularly the jumps observed in crisis periods and the trend of reverting back to average later are supportive of Mougeout's opinions. 


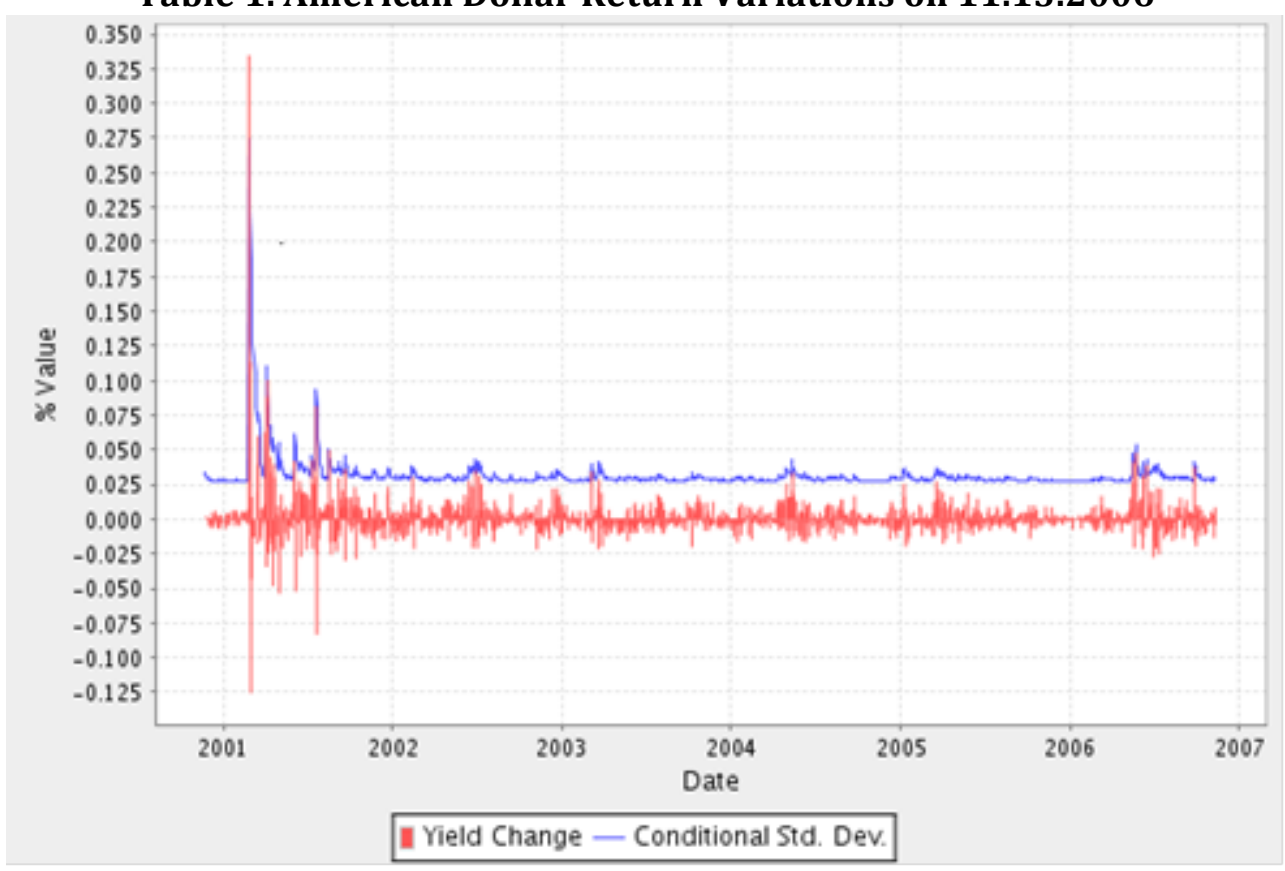

Source: FIA .

\section{LITERATURE REVIEW}

Recently research on volatility has attracted much attention from financial markets and there is a lot of research on this topic. When looking at the development of these studies over years Akgiray (1989) provides evidences showing that compared to EWMA and historical volatility calculations ARCH (Autoregressive Conditional Heteroscedasticity) and GARCH models come up with better forecasts. Tse (1991) has applied EWMA, GARCH and ARCH methods in forecasting the volatility of Japan securities exchange and shown that EWMA was the best method.

In a study conducted by Tse and Tung (1992) on forecasting the volatility of Singapore securities exchange EWMA was shown as the best performing forecasting method. In Franses and Dijk (1996) study, where authors used GARCH models to estimate stock market volatility QGARCH and GJR GARCH models were compared. After disregarding extreme market shocks QGARCH had the best forecasting model. In Kumar's (2006) study on the Indian stock exchange EWMA volatility forecasts performed better than GARCH forecasts. In the study by Minkah (2007) volatility forecasts of the DJ-AIG mal Index, the S\&P 500 Index, OMXS30 Index, the exchange rate between Ghanaian Cedi and American dollar as well as returns of 3-months US treasury bonds have been compared from the perspectives of GARCH, EWMA and Historical volatility.

In these forecasts, it has been determined that compared to historical variance, GARCH models produce more accurate results in long term volatility forecasts. In Akar's (2007) study on forecasting the volatility of ISE 100 index, ARCH, GARCH and SWARCH models have been compared and SWARCH models were found to have relatively less persistency compared to ARCH and GARCH models. Likewise in the same study SWARCH models have been found to provide better predictions. In Chou, Chou and Liu's (2009) theoretical study based on range volatility, the authors point out that demand from the financial markets had led to a rapid increase in the number of such studies. 


\section{Volatility Models}

Poon and Granger (2003) divide Volatility models into two main categories; those models based on time series and those models based on options. Among the models based on time series there are the models based on past volatility. For example, historical averages of squares of returns, MA, ARCH, GARCH, EGARCH, GJR GARCH and stochastic models. Among the options based models are Implied Volatility (IV) and Black Scholes models. In addition to these models, the ones that are based on historical price ranges are also heavily used in volatility forecasts. As an example, volatility forecast models that are also called HL (High Low) that use the highest and lowest price ranges are also used in forecasting volatilities.

Despite the fact that the forecasts based on volatility containing a certain range were introduced by Mandelbrot (1971) in the early 1980s, it was Parkinson (1980) who subsequently provided evidence showing that range volatility is more efficient than models based on classic returns.

Academics continue to debate the relative merits of volatility models. For instance, while time series models are said to capture the continuity of the volatility, options based models are considered useful for future looking predictions (Benavides and Capistran, 2008, p. 2). On the other hand, in order to be able to make forecasts based on time series models historical data are use. Here, there is the volatility which is called unconditional volatility which holds that variance is constant and it does not change over time. The conditional volatility models however, incorporate into their models the fact that variance changes over time. In practice the majority of studies about volatility forecasts are conducted based on the same or similar volatility models. When the volatility coefficients obtained from GARCH and EWMA models are compared, it turns out that the forecasts are very similar to each other, meaning that this is not an effective way of comparing the models. With this in mind, together with GARCH models our study also makes calculations and comparisons on volatility models that show different features like HL volatility. Many volatility calculations are based on time series using intraday returns. These calculations are performed by using daily, weekly, monthly and annual data. While these analyses and calculations are made it is inevitable to use technological tools or software.

The volatility models and notations employed in this study are as follows:

\section{MA (Moving Average)}

A volatility forecast which contains historical or $\mathrm{n}$ period data is the square root of standard error.

$$
\sigma_{t+1}^{2}=\frac{1}{n} \sum_{s=t-+1}^{t}\left(r_{s}-\mu\right)^{2}
$$

In this model, rs, denotes asset returns in period $s$ and $\mu$ shows average return of the assets. The advantage of this forecast method is that its calculation is easy and it does not involve any element other than the time frame that the volatility is measured. When the contained time frame " $n$ " is shorter, the effect of volatility is larger and it becomes critically important for the relevant low or high rate explanations. In the MA model, different observations in variance forecast are equally weighted. In case of a financial shock, however, the volatility will sharply increase or decrease in the negative direction. 


\section{EWMA (Exponential Weighted Moving Average)}

This method is mostly used in risk management calculations. Its calculation is performed by taking the square root of the data points. The lambda multiplier used in the model is known as "decay factor" (smoothing constant) and it takes values between 0 and 1. Model (Hull, 2000, p. 370);

$$
\sigma_{n}^{2}=\lambda \sigma_{n-1}^{2}+(1-\lambda) u_{n-1}^{2}
$$

In this model the volatility $\sigma$ for the nth day is calculated from $\sigma n-1$ (which is realized n-1 day ago) and un-1 shows the most recent changes in the market. When the calculations are made we need to calculate a new $\mathrm{u} 2$ in case a new market observation is taken or there is a variation and we need to use variance forecast, as well. At the end, the old variance rate or old market return variation will lose its significance.

EWMA model has been developed to monitor the changes taking place in financial markets and it is built around the fact that variance changes over time. If we assume that there happened a large movement in the market variation n-1 days ago, in this case $u 2 n-1$ gets enlarged, too. Here, for $n$ days the volatility of the market is estimated. In the calculations $\lambda$ coefficient, which is one of the fundamental parameters, is used. This coefficient takes a value between 0 and 1 . As it approaches to 1 the oldest historical data are given more weight. As the coefficient moves away from 1 the new and closer historical data are given more weight. Because it is the most important parameter that can be changed in the model, determining the optimum lambda coefficient is very important.

This method geometrically weights the falls in the markets. It assigns more weights to recent falls than the long standing ones. This helps to see the impact of recent volatility on the market. As the lambda coefficient draws closer to 1 however, effect of all the historical data taken into consideration is observed and effect of recent volatility might not be clearly seen.

This weighting plan also helps to capture dynamic features of the data. When making the calculations RiskMetrics recommends using a general decay factor for all the assets in a given period. The smoothing coefficient is 0,94 for daily data and it is 0,97 for monthly data. When the same decay factor is used in the calculations, the model simplifies the calculations with wide covariance matrix and it eliminates the problem of volatility forecast perspective (Suganuma, 2000, p. 4).

\section{GARCH (1.1) (Generalized Autoregressive Conditional Heteroskedasticity)}

In this model, first proposed by Bollerslev (1986) and is known as GARCH (1.1) shows return rates in volatility forecasts and all the returns are given the same weight in the equation. When the same returns are given weights at the current volatility level and the most recent data are given more weights the model becomes as follows:

$$
\sigma_{n}^{2}=\sum_{i=1}^{m} \alpha_{i} u_{n-i}^{2}
$$

In the above model, $\alpha$ i denotes the weights assigned to observations i days ago. $\alpha \mathrm{i}$ is a positive value because when $\alpha \mathrm{i}<\alpha \mathrm{j}$ and $\mathrm{i}>\mathrm{j}$ we want to give less weight to old data. The sum of the weights should be 1(Hull, 2000, p. 370). 


$$
\sum_{i=1}^{m} \alpha_{i}=1
$$

When the long term volatility assumption is incorporated into the previous model the new model becomes as follows:

$$
\sigma_{n}^{2}=y V+\sum_{i=1}^{m} \alpha_{i} u_{n-i}^{2}
$$

$\mathrm{V}$ denotes the long term volatility level. Y, however, is used in weighting of $\mathrm{V}$ as the sum of weights should be 1 .

$y+\sum_{i=1}^{m} \alpha_{i}=1$

The model which was first proposed by Engle (1982: 987) and is known as ARCH (m) model calculates the volatility that is based on $m$ observations and long term average variance rate. The old observations are given less weight. It can be expressed as $\omega=\mathrm{yV}$. In this case model becomes as follows:

$\sigma_{n}^{2}=\omega+\sum_{i=1}^{m} \alpha_{i} u_{n-i}^{2}$

GARCH (1.1) model however, calculates the volatility by using long term variance rate ( ), volatility rate of the previous day ( $\sigma n-1)$ and return changes (un-1). In this case GARCH (1.1) model becomes as follows:

$\sigma_{n}^{2}=\omega(y V)+\alpha u_{n-1}^{2}+\beta \sigma_{n-1}^{2}$

In the above model y is used in weighting of $\mathrm{V}, \alpha$ is used in weighting of return changes ( ) and $\beta$ value is used in weighting of volatility. The sum of coefficients used in weighting in the model should be 1 .

$y+\alpha+\beta=1$

EWMA model is a special form of GARCH model. In this model $y=0, \alpha=1-\lambda$, and $\beta=\lambda$. In addition to this, GARCH (1.1) model calculates the volatility with observations of latest return changes and variance rate. GARCH (1.1) is the most popular form among the GARCH models (Hull, 2000, p. 372). When GARCH model is written instead of $y \mathrm{~V}$, $\omega$ can be used. In such a case the model turns out to be as follows:

$$
\sigma_{n}^{2}=\omega+\sum_{i=1}^{p} \alpha u_{n-i}^{2}+\sum_{i=1}^{q} \beta \sigma_{n-i}^{2}
$$

In the calculations based on this model firstly parameters should be determined $(\omega, \alpha, \beta)$. At the end the long term volatility coefficient is calculated as $y=1-\alpha-\beta$. From this equation the long term variance rate (V) is calculated as $\omega / \mathrm{y}$. According to GARCH (1.1) process, for the volatility forecast $\alpha+\beta<1$ should be satisfied. Otherwise, long term variance will be negative. 


\section{Gjr Garch}

This model is similar to Quadratic GARCH (QGARCH) model that was developed by Sentena. GJR-GARCH model has been developed by Glosten, Jaganathan ve Runkle (1992) with the assumption that positive and negative shocks will not have the same effects on conditional variance. This model also shows model asymmetry in the GARCH model.

$$
\sigma_{n}^{2}=\omega+\sum_{i=1}^{q} \alpha_{i} u_{n-i}^{2}+y u_{n-i}^{2} d_{n-i}+\sum_{j=1}^{p} \beta_{j} \sigma_{n-j}^{2}
$$

The dummy variable (dn) in the above variance equation becomes $d n=1$ when $u n<0$, and it becomes equal to zero $(\mathrm{dn}=0)$ otherwise. Therefore the asymmetry parameter y becomes significant when $d n=1$. By satisfying the conditions $P=q=1, \omega>0, \alpha>0, \beta>0, \alpha+y>0$ sufficiency for having positive conditional variance is fully established. In the model, effect of good and bad news on conditional variance is assessed. Effect of good news (un $>0$ ) is shown by $\alpha$ and effect of bad news (un $<0$ ) is shown by $(\alpha+y)$. If the parameter $y>0$ then it is said bad news increase the volatility and in case of $y$ \# 0 then effect of the news on volatility is not symmetric (Mazibas, 2005, p. 8).

\section{IGARCH}

IGARCH (Integrated Generalized Autoregressive Conditional Heteroskedasticity), is a limited version of GARCH model. In this model sum of the parameters should always be 1 . Therefore GARCH process involves unit root.

$$
\sum_{i=1}^{p} \beta_{i}+\sum_{i=1}^{q} \alpha_{i}=1
$$

\section{High Low (HL) Range Volatility}

The volatility forecasts that are based on price ranges have an important advantage because intraday volatility values can easily be obtained. Calculations based on intraday price ranges can be made over securities, foreign exchange rates and commodities and history of these calculations goes back to year around 1955 (Chou, Chou and Liu, 2009, p. 5).

In order to be able to make HL Volatility calculations the below variables should be known:

$O T=$ opening price for the $t$ trading day,

$C t=$ closing price for the t trading day,

$H t=$ the highest price for the t trading day,

$L t=$ the lowest price for the $t$ trading day,

In volatility calculations closing prices (close to close) are used. The logarithmic return is denoted by $r_{i}=\ln \left(\frac{C_{i+1}}{C_{i}}\right)$, average return is denoted by $\bar{r}=\frac{r_{1}+r_{2}+\ldots . r_{n-1}}{n-1}$ and volatility is denoted by

$$
\sigma=\sqrt{\frac{Z}{n-2} \sum_{i=1}^{n-1}\left(r_{i}-\bar{r}\right)^{2}}
$$

Here, $\sigma$ denotes volatility, $\mathrm{Ci}$ denotes the closing price for the day $\mathrm{t}, \mathrm{n}$ denotes number of historical days used in the forecasting the volatility, ri denotes logarithmic return over day $\mathrm{t}$ and $\mathrm{Z}$ is the number of days, that have closed prices in the historical annual data. Starting from 
this point onwards, Range volatility can be defined as the difference between daily highest and lowest logarithmic price ranges of an asset (Chaou, Chou and Liu, 2009, p. 9).

$R_{t}=\ln \left(H_{t}\right)-\ln \left(L_{t}\right)$

RT shows more persistence than the squared return autocorrelations.

Thus range based volatility forecast methods can be used in lieu of assessment of volatility forecasts that are calculated by using squares of returns.

\section{Historical Open-High-Low-Close Volatility: Rogers Satchell}

Roger and Satchell (1991) have added the drift term to the stochastic volatility process however they have assumed that there is no increase or jump in the opening and they have used opening, closing, highest and lowest prices to come up with a new forecasting model.

$\sigma \sqrt{\frac{Z}{n} \sum\left[\ln \frac{H_{i}}{C_{i}} \ln \frac{H_{i}}{O_{i}}+\ln \frac{L_{i}}{C_{i}} \ln \frac{L_{i}}{O_{i}}\right]}$

\section{Historical Open-High-Low-Close Volatility: Yang Zhang}

In case an increase or jump is observed in the opening price Yang and Zhang (2000) have developed a volatility forecast method which is independent of drift variable and unbiased. This model is the first HL model that is derived from historical volatility and has the minimum error terms. Yang The Yang-Zhang estimator can be considered to be a weighted average of the Roger-Satchell estimator, with regard to the open and close prices.

$$
\begin{array}{ll}
\sigma^{2}=\sigma_{o}^{2}+k \sigma_{c}^{2}+(1-k) \sigma_{r s}^{2} & \mu_{o}=\frac{1}{n} \sum \ln \frac{O_{i}}{C_{i-1}} \\
\sigma_{o}^{2}=\frac{Z}{n-1} \sum\left(\ln \frac{O_{i}}{C_{i-1}}-\mu_{o}\right)^{2} & \mu_{c}=\frac{1}{n} \sum \ln \frac{C_{i}}{O_{i}} \\
\sigma_{c}^{2}=\frac{Z}{n-1} \sum\left(\ln \frac{C_{i}}{O_{i}}-\mu_{c}\right) & \\
\sigma_{R S}^{2}=\frac{Z}{n} \sum\left(\ln \frac{H_{i}}{C_{i}} \ln \frac{H_{i}}{O_{i}}+\ln \frac{L_{i}}{C_{i}} \ln \frac{L_{i}}{O_{i}}\right) \\
k=\frac{0,34}{1+\frac{n+1}{n-1}}
\end{array}
$$

\section{Historical Open-High-Low-Close Volatility: Garman Klass}

Garman Klass (1980) has proposed a new volatility estimator which is based on opening, closing, lowest and highest price information. This model derives its forecasts with the assumptions that there is no jump in the opening price, drift variable is zero and the security price follows historical Brownian motion without drift. 


$$
\sigma=\frac{Z}{n} \sum \sqrt{\frac{1}{2}\left(\ln \frac{H_{i}}{L_{i}}\right)^{2}-(2 \ln 2-1)\left(\ln \frac{C_{i}}{O_{i}}\right)^{2}}
$$

\section{Historical High-Low Volatility: Parkinson}

Rather than two arbitrary points in the series Parkinson (1980) defines an estimator that is based on evidence that intraday price intervals give much more information on future volatility rather than two random points in a series. The model is as follows:

$$
\sigma=\sqrt{\frac{Z}{n 4 \ln 2} \sum_{i=1}^{n}\left(\ln \frac{H_{i}}{L_{i}}\right)^{2}}
$$

\section{TESTING THE VOLATILITY MODELS}

The error statistics defined for volatility models are used to compare the differences between prediction values and actual realized values without taking the sign and size of them into consideration. In comparing the estimator models, the decision as to whether error terms of a model is better than the compared one is made by MSPE -Mean Square Prediction Error test. The significance of the study will increase in case the results in this test is smaller than the $t$ table while the same significance will be achieved if the test statistics are greater than table in Diebold, Mariano (1996) and West (1995) test (DMW) and Clark and West (CW) (2006) test. Particularly CW test is one of the best testing models that cover and compare the nested and intertwined estimator models. Accordingly, error prediction statistics are defined as follows:

$$
M S P E=\left[\sum_{i=1}^{n}\left(y_{t+i}-\hat{y}_{t+i}\right)^{2}\right]
$$

$y_{t+i}=$ explains compared error term, $\hat{y}_{t+i}=$ explains forecast error term of the model.

Although MSPE test result is not considered adequate criterion on its own it is nonetheless an important criterion showing the average error performance. Having a small value for this criterion is important for the performance and efficacy of the model. The comparison between models can be made with respect to maximum criterion of $\chi 2$ and t statistics values. In this study only t statistics based results have been used. Also, with the MSPE the test statistics of the below two models be compared:

$$
\begin{array}{ll}
H_{0}: \sigma_{1}^{2}-\sigma_{2}^{2}=0 & D M W=\frac{\bar{f}}{\sqrt{P^{-1} V}} \\
H_{1}: \sigma_{1}^{2}-\sigma_{2}^{2}>0 & C W=\frac{f}{\sqrt{P^{-1} V}} \\
f=y_{t+i}-\left(y_{t+i}-\$_{t+i}\right) &
\end{array}
$$


$\bar{f}=\sigma_{1}^{2}-\sigma_{2 a d j}^{2}$

$V=P^{-1} \sum(f)^{2}$

Where;

P-1: denotes forecast of error terms and number of these forecasts;

$\bar{f}$ : denotes the adjusted difference between the models and MSPE.

As a result of the test statistics, rejecting the null hypothesis puts forward that critical values are exceeded and alternative hypothesis is accepted therefore there is a difference between compared models or criteria. Another important point in measuring the performance is how much the critical value exceeds the threshold value.

\section{RESEARCH AND FINDINGS}

In this study volatilities of ISE 30 and USD/TRL exchange rate have been estimated between the dates $06 / 30 / 2008$ and $06 / 30 / 2009$. The statistics pertaining to used data are presented in Table 2.

Table 2. Summary Statistical Results

\begin{tabular}{|l|l|l|l|l|l|l|l|l|}
\hline & \multicolumn{9}{|l|}{ ISE 30 } & \multicolumn{3}{l|}{ USD/TRL } \\
\hline & Open & High & Low & Close & open & High & low & close \\
\hline Minimum & $27.095,21$ & $27.185,07$ & $26.466,76$ & $27.062,22$ & 1,15 & 1,16 & 1,15 & 1,15 \\
\hline Maximum & $54.434,67$ & $54.564,50$ & $52.964,50$ & $53.513,90$ & 1,80 & 1,82 & 1,78 & 1,81 \\
\hline Skewness & 0,39 & 0,37 & 0,39 & 0,38 & $-0,63$ & $-0,66$ & $-0,64$ & $-0,64$ \\
\hline Kurtosis & $-1,08$ & $-1,12$ & $-1,09$ & $-1,13$ & $-1,03$ & $-0,99$ & $-1,04$ & $-1,03$ \\
\hline Average & $38.756,03$ & $39.339,08$ & $38.112,91$ & $38.733,33$ & 1,49 & 1,51 & 1,48 & 1,49 \\
\hline
\end{tabular}

Skewness and kurtosis values explain whether the distribution is normally distributed or not. Accordingly, if skewness value is 0 and kurtosis value is 3 then the distribution is normal.

The volatility tables of ISE 30 index and USD/TRL exchange rate in different models are shown in Table 3 and Table 4.

Table3. Volatility Outlook of ISE 30 Index In Different Models between 06/30/2008- 6/30/3009

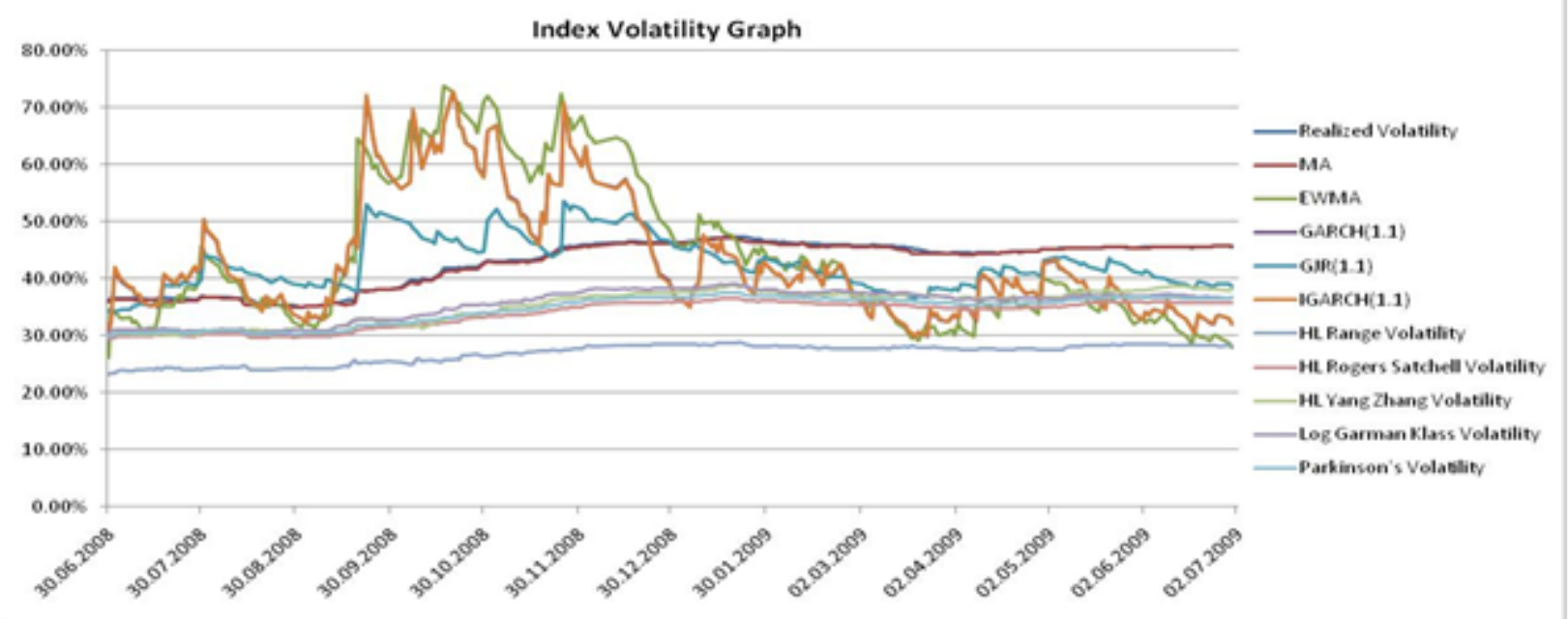


Table 4. Volatility Outlook of USD/TRL Exchange Rate In Different Models Between 06/30/2008 $-06 / 30 / 3009$

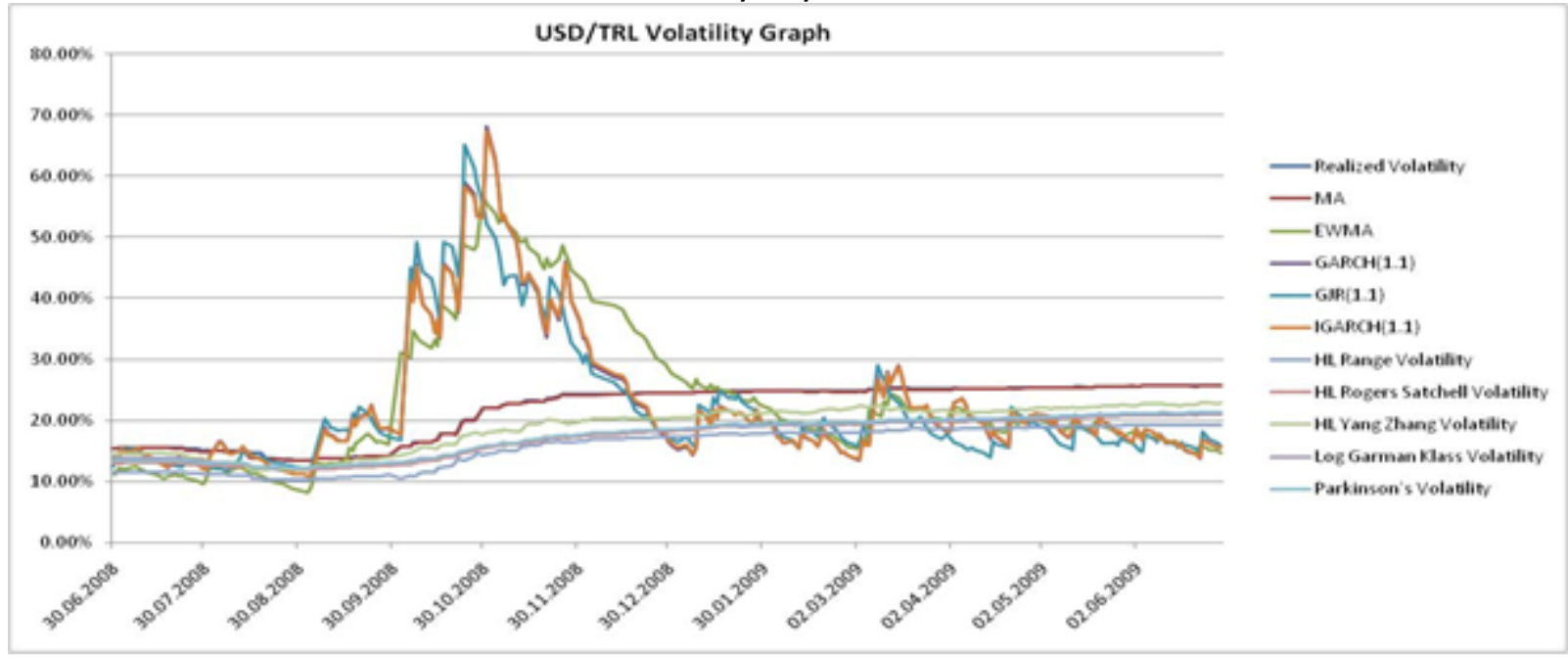

Table 5. Volatility Models Performance Tests and Their Results

\begin{tabular}{|c|c|c|c|}
\hline & & IМКВЗО & USD/TRL \\
\hline$\overline{G A R C H(1.1)}$ & MSPE & 0.0131 & 0.0132 \\
\hline \multirow{3}{*}{$M A$} & MSPE & 0.0059 & 0.0000 \\
\hline & DMW & 2.0220 & -0.2907 \\
\hline & CW & 0.3615 & 0.0236 \\
\hline \multirow{3}{*}{$E W M A$} & MSPE & 0.0175 & 0.0126 \\
\hline & DMW & 0.7939 & 0.6261 \\
\hline & $\mathrm{CW}$ & 0.6799 & 0.1952 \\
\hline \multirow{3}{*}{ GJR(1.1) } & MSPE & 0.0029 & 0.0131 \\
\hline & DMW & -0.3896 & -0.6268 \\
\hline & CW & 1.0460 & 0.1555 \\
\hline \multirow{3}{*}{ IGARCH(1.1) } & MSPE & 0.0131 & 0.0131 \\
\hline & DMW & 0.2298 & 0.1852 \\
\hline & $\mathrm{CW}$ & -0.3864 & 0.0564 \\
\hline \multirow{3}{*}{$\begin{array}{l}\text { HL Range } \\
\text { Volatility }\end{array}$} & MSPE & 0.0261 & 0.0037 \\
\hline & DMW & -4.0741 & -2.4077 \\
\hline & CW & 0.6267 & 0.9969 \\
\hline \multirow{3}{*}{$\begin{array}{c}\text { HL Rogers } \\
\text { Satchell } \\
\text { Volatility }\end{array}$} & MSPE & 0.0083 & 0.0025 \\
\hline & DMW & -3.1347 & -2.0183 \\
\hline & $\mathrm{CW}$ & 1.3083 & 0.6734 \\
\hline \multirow{3}{*}{$\begin{array}{c}\text { HL Yang } \\
\text { Zhang } \\
\text { Volatility }\end{array}$} & MSPE & 0.0060 & 0.0009 \\
\hline & DMW & -2.7793 & -1.4021 \\
\hline & CW & 0.7586 & 0.6475 \\
\hline \multirow{3}{*}{$\begin{array}{c}\text { Log Garman } \\
\text { Klass } \\
\text { Volatility }\end{array}$} & MSPE & 0.0056 & 0.0023 \\
\hline & DMW & -2.7999 & -1.9431 \\
\hline & $\mathrm{CW}$ & 0.6626 & 0.5666 \\
\hline \multirow{3}{*}{$\begin{array}{c}\text { Parkinson's } \\
\text { Volatility }\end{array}$} & MSPE & 0.0070 & 0.0022 \\
\hline & DMW & -2.9804 & -1.9187 \\
\hline & $\mathrm{CW}$ & 0.6290 & 0.6239 \\
\hline
\end{tabular}

T table values: $1 \%=3.3414 ; 5 \%=1.6510 ; 10 \%=1.2849$

When the results in Table 5 are analyzed it is seen that index volatility and exchange rate volatility do not show a similar distribution. In the performance tests however, the model taken as the base model both in ISE 30 and USD/TRL is GARCH (1.1) model. In the situations when test statistics are significant it can be said that error performance of the compared model 
is different from error performance of GARCH (1.1) model. In the presented table it is seen that index is more volatile than exchange rate. At 1\% confidence level and according to t statistics, table shows that in the models where volatility of index was estimated there is significant difference between GARCH (1.1) model and HL Range Volatility, HL Rogers Satchell Volatility, Parkinson's Volatility, Log Garman Klass Volatility, HL Yang Zhang Volatility and MA, respectively. For the index, there is no significant difference between using EWMA or other GARCH models and using GARCH (1.1) in the same period. When we look at the same table for USD/TRL exchange rate, at 1\% confidence level and according to t statistics, only the HL Range Volatility model has posted a significant difference however employing other methods has not shown superiority to usage of GARCH (1.1) model. Therefore, for USD/TRL, with respect to the t statistics at 5\% confidence level it can be said that HL Range Volatility, HL Rogers Satchell Voltility, Log Garman Klass Volatility and Parkinson's Volatility have shown more effective and significant performance than GARCH (1.1). Here, the two other points that draw attention are the followings: Firstly, between ISE 30 and USD/TRL in the models that were compared with GARCH (1.1) base model the effectiveness, degree of effectiveness and ranking of models have differed. Secondly, as it can be understood from error performance tests, while one model is valid and it shows good performance with ISE 30 it can turn into an unimportant and ineffective indicator in USD/TRL. Particularly this finding has the important implications for the financial institutions having different underlying assets and risk factors and it shows that they should not make estimates and comparison always with the same models.

\section{SUMMARY AND CONCLUDING REMARKS}

The global financial system has been rapidly changing and developing. Doubtlessly, the basic elements having an impact on these changes and developments are information and technology as the instruments used in financial markets have been increasingly becoming more dependent on technical and econometric calculations and they intensely use more advanced technology. Therefore, the models to be used in the calculations show differences. Within this context, in forecasting financial market variations and changes, in addition to such different volatility forecasting models as historical calculation, prediction based calculations, EWMA and GARCH, the Historical HL volatility models are used, as well. No matter which model is used the ultimate objective is to accurately estimate the volatility.

Different volatility estimates are made for the different underlying assets like exchange rate, interest rate, index and commodity that are traded in financial markets. While the models used in these forecasts provide similar results to each other, this inevitably results in lessened significance of the tests made and studies conducted. Because, in the absence of meaningful differences between the models and obtained results the positions taken based on these estimates lose their effectiveness, as well. Therefore, what is required is to determine the most suitable volatility model for each underlying asset and be able to apply the models that have significant differences from others.

This study shows that in the volatility forecast study over ISE 30 index and USD/TRL exchange rate there has been no significant difference between GARCH (1.1) model and other GARCH models and EWMA model because fundamental reasoning of the models have the similar characteristics. However, significant differences have been found between the models based on Historical HL volatility and GARCH (1.1) model. For example, in forecasting the ISE 30 index volatility at $1 \%$ confidence level as in the case of HL Range Volatility, HL Rogers Satchell Volatility, Parkinson's Volatility, Log Garman Klass Volatility, HL Yang Zhang Volatility.

Additionally, for USD/TRL exchange rate t statistics at 5\% confidence interval, the models that have generated more effective and significant performance than GARCH (1.1) are HL Range Volatility, HL Rogers Satchell Volatility, Log Garman Klass Volatility and Parkinson's Volatility. 
To be able to take an accurate position in the financial markets and to make predictions regarding future events, accurate volatility forecasts are helpful now and into the future. Otherwise, efficacy of the calculations made or positions taken will be diminished.

International trade has inherent risks for importers and exporters due to different legal systems and conventions, governmental interferences and transactors' inability to know enough each other. Letter of credit (hereinafter LC) is a tool providing simultaneous protection for both importers and exporters by utilizing the banks' reputation in international transactions.

LC mechanism provides benefits to the exporters as they are entitled to a guaranteed payment following the presentation to the bank of complying documents. But the high frequency rates of discrepancies in the documents presented to the banks create negative impacts on LC as a guaranteed payment mechanism. The present study aims at empirically investigating the possible causes of discrepancies in export documents. For this purpose, a survey was conducted on 460 companies in Istanbul Chamber of Commerce 500 List Companies (ICI 500). Sample frame, thus, features a capacity to reflect the pervasiveness of the findings for wellknown, large scale industrial companies with a letter of credit experience in Turkey.

The following second section of the study will inquire the basic operating process of the LC as a payment mechanism in international trade together with the implication of the non-complying documents in the process. The third section will provide literature review. The fourth section will present the methodology and the results of the survey study. The study will end by the summary and conclusion section.

\section{References}

Akar Cüneyt, (2007), Volatilite Modellerinin Öngörü Performansları: ARCH, GARCH ve SWARCH Modellerinin Karşılaştırılması, İşletme fakültesi Dergisi, Cilt: 8, Sayı:2, s.201-217.

web.deu.edu.tr/isletme/ifddergi/web_files/82201217.pdf(07.12.2009).

Benavıdes Guillermo \& Capıstran Carlos, (2008), Forecasting Exchange Rate Volatility: The Superior Performance of Conditional Combinations of Time Series and Option Implied Forecasts, http://ssrn.com/abstract=1260095 (30.11.2009).

Bollerslev, T. (1986) “Generalized Autoregressive Conditional Heteroskedasticity,” Journal of Econometrics, Vol. 31, pp. 307-327.

Bolgün Evren \& Akçay Barış, (2009), Risk Yönetimi, Scala yayıncılık, İstanbul.

Brooks Chris \& Persand Gita, (2003), Volatility Forecasting for Risk Management, Journal Of Forecasting, Published online 9 October 2002 in Wiley InterScience (www.interscience.wiley.com). DOI: 10.1002/for.841

Butler Cormac, (1999), Matering Value at Risk, Financial Times Prentice Hall, Great Britian.

Cheong Chongcheul, Does the risk of Exchange rate fluctuation realy affect international trade flow between countries?, Economics Bulletin, Vol. 6, No: 4, s.1-8.

http://www.economicsbulletin.com/2004/volume6/EB-04F10002A.pdf(05.04.2008)

Chou Ray Yeutien, CHOU Hengchih \& LIU Nathan, (2009), Range Volatility Models and Their Applications in Finance, Institute of Economics, Academia Sinica, Taiwan.

http://www.centerforpbbefr.rutgers.edu/Taipei\%20PBFR\&D/01-16-09\%20papers/1-

4\%20Nathan\%20Liu_Range_Review_NCTU.pdf(30.11.2009).

Clark, Todd E. \& West, Kenneth D., (2006), "Using out-of-sample mean squared prediction errors to test the martingale difference hypothesis," Journal of Econometrics, Elsevier, vol. 135(1-2), pp. 155-186.

Diebold, Francis \& MARIANO Roberto, (1995), "Comparing Predictive Accuracy," Journal of Business \& Economic Statistics, American Statistical Association, vol. 13(3), p. 253.

Engle, R. F. (1982), “Autoregressive conditional heteroscedasticity with estimates of the variance of United Kingdom inflation,” Econometrica, 50, pp. 987-1007. 
Franses Philip Hans \& DIJK Dick Van, (1996), “Forecasting Stock Market Volatility Using GARCH Models”, Journal of Forecasting, Vol.15, pp. 229-235.

Garman, M. \& M. Klass, (1980), “On the estimation of security pricevolatilities from historical data,” Journal of Business, 53, pp. 67-78.

Giannapoulos Kostas \& Eales Brian, (1196), Futures and Options World, April., http://currencies.thefinancials.com/FAQs1b.html(22.02.2008).

Glosten, L. R., R. Jagannathan \& D. E. Runkle (1992) “On the Relation Between the Expected Value and Volatility of the Nominal Excess Return on Stocks”, Journal of Finance, Vol. 46, pp. 1779-1801.

Hampton David, (2005), Volatility and Using GARCH (1.1) to Forecast Future Volatility, CERAM Sophia Antipolis, European School of Business.

Hull John C., (2000), Options, Futures, Other Derivatives, Fourth Edition, Prentice Hall International Inc., U.S.A.

Kumar S.S., (2006), Forecasting Volatility, Evidence from Indian Stock and Forex Markets, IIMK/WPS/08/FIN/2006/06.www.dspace.iimk.ac.in/bitstream/2259/289/1/ForecastingVolatility.pdf(15.04.20 08).

Mandelbrot B. (1971), "When can price be arbitraged efficiently? A limit to Validity of the random walk and martingale models," Review of Economics and Statistics, 53, pp. 225-236.

Mazıbaş Murat (2005), İMKB Piyasalarındaki Volatilitenin Modellenmesi ve Öngörülmesi: Asimetrik GARCH Modelleri ile bir Uygulama, www.ekonometridernegi.orgbildirilero16s3.pdf(02.12.2009)

Mınkah Richard (2007), U.U.D.M Project Report 2007 / 7, Forecasting Volatility, httpwww. math. uu.seresearchpubMinkah1.pdf (02.03.2007)

Mougeot Nicolas, (2005), Volatility Investing Handbook, Equities \& Derivatives Research, BNP Paribas, www.eqd.bnpparibas.com (02.11.2009).

Parkınson M. (1980), "The extreme value method for estimating the variance of The rate of return," Journal of Business, 53, pp. 61-65.

Pereira Ricardo (2007), Forecasting Portuquese Stock Market Volatility, httpwww.fma.org ChicagoPapersForecastingVolatility_RicardoPereira.pdf(02.02.2007.

Poon, S-H. \& GRANGER, C.W.J. (2003). Forecasting Volatility in Financial Markets: A Review. Journal of Economic Literature, 41, pp. 478-539.

Poon Ser-Huang, (2005), A Practical Guide to Forecasting Financial Market Volatility, Wiley Finance, John Wiley \& Sons Ltd., England.

Rıskmetrıcs “Technical Document”, (1996), Fourth Edition, Morgan Guaranty Trust Company of New York.

Rogers L. \& S. Satchell (1991), “Estimating variance from high, low and Closing prices,” Annals of Applied Probability, 1, pp. 504-512.

Schmıdt Udo-Mohr, (1995), Volatility Forecasting with Nonlinear and Linear Time Series Model: A Comparison, Frankfurt, Germany.

Suganuma Ricardo, (2000), Reality Check For Volatility Models, University of California, San Diego Department of Economics, httpwww.econ.puc-rio.brPDFsuganuma.pdf(12.02.2007)

Tse, Y. K. (1991). Stock Returns Volatility in the Tokyo Stock Exchange, Japan and the World Economy, 3, pp.285298.

Tse, Y. K. \& Tung S. H. (1992). Forecasting Volatility in the Singapore Stock Market, Asia Pacific Journal of Management, 9, 1-13.

Ünal Özlem Serpil, (2009), Döviz Kuru Oynaklığının Öngörülmesi ve Risk Yönetimi: Türkiye Örneği, Uzmanlık Yeterlilik Tezi, TCMB, Piyasalar Genel Müdürlüğü, Ankara.

West, Kenneth D., (1996), “Asymptotic Inference about Predictive Ability” Econometrica, 64, pp. 1067-1084.

Yang D. \& Q. Zhang, (2000), “Drift-independent volatility estimation based on high, low, open, and closing Prices,” Journal of Business, 73, pp. 477-491. 